\title{
FGI Study on the Counseling Experience of Sexual Minority Counselors
}

\author{
Jeang-Nam Kim \\ Dept. Counseling Psychology Science, Tongmyong Univ., 428 Sinseon-ro, Nam-gu, \\ Busan, Republic of Korea \\ nam630@tu.ac.kr
}

\begin{abstract}
The purpose of this study was to find out the implications of effective intervention methods for domestic sexual minority clients. To that end, focus group interviews were conducted on the counseling experiences of counselors of specialized sexual minority counseling agencies and the contents of the interviews were analyzed based on the Consensual Qualitative Research (CQR) method. Study participants were 10 counselors from specialized sexual minority counseling agencies. As a result of the analysis, a total of seven areas were created and 35 subcategories were derived from individual areas. Typically appeared answers included 'Sexual minorities are under minority stress in addition to general stress' and 'Sexual minorities do not feel even counseling spaces safe', and the study participants reported a difficulty as counselors, which was their 'great sense of helplessness felt because the client's problems were social structural problems'. They answered that effective intervention methods were "interventions giving priority to the prevention of trauma reexperience" and "an integrated approach combining diverse theories and techniques". The study participants reported that a change is shown by their clients after counseling was 'enhancement of psychological stability through self-acceptation'. Matters that must be observed by sexual minority counselors were reported as 'observing basic counselor ethics', 'mandatory completion of gender-related education', 'acquiring and providing sufficient knowledge as a counseling specialist', and 'self-checking and reflecting as a counselor'. Finally, the results of this study were discussed.
\end{abstract}

Keywords: Sexual minority, Counselor, Specialized sexual minority counseling agencies, FGI

\section{Introduction}

Because of the stress resulting from social prejudice and discrimination, homosexuals seek counseling at a rate higher than the average of the whole population [1]. The reasons why South Korean counselors have low ratios of experience in counseling homosexual clients should be diverse, but one of the reasons may be their failure to recognize their experience in counseling homosexual clients because they do not recognize their clients' sexual orientation [2]. Homosexual clients may be reluctant to disclose their sexual orientation to the counselor when the counselor impliedly reveals their prejudice towards heterosexuals due to their

Article History:

Received (November 29, 2019), Review Result (January 5, 2020), Accepted (February 11, 2020) 
heterosexism such as designating the partner of the client as a person of the opposite sex [3][4].

Therefore, counselors should develop sensitivity to sexual orientation and competence in sexual minority counseling [2][5][6][7][8][9][10]. In a study conducted by [11], counselors were found to feel a sense of lack of understanding of sexual minorities and a sense of burden from counseling while they were experiencing counseling sexual minorities.

Foreign studies have shown that educational programs to promote homosexual counseling competence have direct effects on improving counselors' competence [12][13]. Given that the accumulation of counseling experience in the general counseling area does not always lead the development of expertise in a certain area, efforts and interest are needed very much so that systematic education and training can be provided to cultivate competent sexual minority counselors in South Korea too.

\section{Study method}

\subsection{Focus group interview}

In this study, the focus group interview analysis was selected to find implications for effective intervention strategies for sexual minority clients in South Korea. Focus group interviews are a qualitative study and analysis method that collects data generated through interactions between people who undergo the same experience and draws conclusions from the data [14]. The focus of a focus group is on discussion based on the topic raised by the researcher who plays the role of a presenter and obtaining data that cannot be easily drawn by other methods by actively utilizing interactions within the group [15]. While individual interviews have the advantage of enabling in-depth exploration of subjective experiences, group interviews have the advantage of enabling not only the examination of experiences in various aspects through interaction processes but also hearing diverse opinions on improvement points through the process of mutual discussion.

\subsection{Study participant}

Ten counselors who were counseling sexual minorities at specialized sexual minority counseling agencies. Interviews with the study participants were carried out after receiving their written agreement to participate in the study. Information on the counselors who participated in this study are as shown in [Table 1].

Table 1. Demographic characteristics of study participants

\begin{tabular}{|c|l|l|c|c|c|c|}
\hline Study participant & Sex & $\begin{array}{c}\text { Sexual } \\
\text { orientation }\end{array}$ & Age & $\begin{array}{c}\text { Educational } \\
\text { background }\end{array}$ & $\begin{array}{c}\text { Counseling } \\
\text { experience }\end{array}$ & $\begin{array}{c}\text { Sexual minority } \\
\text { counseling } \\
\text { experience }\end{array}$ \\
\hline Study participant 1 & Female & Heterosexual & 32 & Master & $\begin{array}{c}5 \text { years } 9 \\
\text { months }\end{array}$ & $\begin{array}{c}2 \text { years } 4 \\
\text { months }\end{array}$ \\
\hline Study participant 2 & Female & Heterosexual & 43 & $\begin{array}{c}\text { Doctorate } \\
\text { course }\end{array}$ & $\begin{array}{c}3 \text { years } 6 \\
\text { months }\end{array}$ & 7 months \\
\hline Study participant 3 & Male & Gay & 30 & Master & $\begin{array}{c}3 \text { years } 6 \\
\text { months }\end{array}$ & 3 years \\
\hline Study participant 4 & Female & Heterosexual & 30 & Master & 6 years & 7 months \\
\hline Study participant 5 & Female & Heterosexual & 30 & Master & 15 years & 7 months \\
\hline
\end{tabular}




\begin{tabular}{|c|l|l|l|c|c|c|}
\hline Study participant 6 & Female & Lesbian & 34 & $\begin{array}{c}\text { Completed a } \\
\text { doctorate course }\end{array}$ & $\begin{array}{c}10 \text { years 3 } \\
\text { months }\end{array}$ & $\begin{array}{c}10 \text { years 3 } \\
\text { months }\end{array}$ \\
\hline Study participant 7 & Female & Heterosexual & 36 & Doctor & $\begin{array}{c}10 \text { years } 2 \\
\text { months }\end{array}$ & 8 years \\
\hline Study participant 8 & Female & Heterosexual & 31 & Master & 6 years & 6 years \\
\hline Study participant 9 & Female & Heterosexual & 36 & $\begin{array}{c}\text { Completed a } \\
\text { doctorate course }\end{array}$ & $\begin{array}{c}11 \text { years } 2 \\
\text { months }\end{array}$ & 6 years \\
\hline Study participant 10 & Female & Heterosexual & 30 & Master & $\begin{array}{c}3 \text { years } 6 \\
\text { months }\end{array}$ & 3 years \\
\hline
\end{tabular}

\subsection{Qualitative analysis method for interview contents}

Interview contents were recorded under the consent of the participants and verbatim records were prepared. The data from which personal information was deleted were analyzed by three experts with rich experience in qualitative analysis in the CQR method. The concrete procedure of the CQR method is presented as follows.

\subsubsection{Data preparation}

Focus group interviews were conducted with 10 counselors from specialized sexual minority counseling agencies. Verbatim records were made from the data obtained through the focus group interviews after removing parts related to secrets and the verbatim records were checked with individual study participants to prepare revised verbatim records according to the participants' opinions to correct, add, or delete the contents.

\subsubsection{Coding of domains}

The process of domain coding is a process of grouping similar contents of 10 verbatim records into domains. The raters reviewed the given verbatim records individually in advance to classify the records into appropriate domains. Thereafter, agreements and disagreements between individual raters were checked and the most appropriate domains were determined through a process of agreement. As a result, a total of seven domains appeared.

\subsubsection{Coding of core ideas}

The process of coding of core ideas is a process of summarizing the raw data into a more concise core idea. As with the coding of domains, individual raters individually developed core ideas in advance. Thereafter, the three raters gathered to check agreements and disagreements and make agreements. As a result, a total of 35 categories in 7 domains appeared.

\subsubsection{Results}

Results were derived through first stability checks, cross-analysis, and second stability checks of the results from the above-mentioned processes.

\subsection{Ethical consideration}

The following ethical considerations were carried out. First, the study was conducted after review by the IRB. Second, the study participants were encouraged to read the written agreement to participate in the study containing the purpose of the study and study ethics and 
the agreement was received only from those who voluntarily wanted to participate in the study to conduct the study with them. The written agreement to participate in the study also contained the promise for confidentiality, the fact that the participants had the right to discontinue the interview if they wished to discontinue the interview during their participation in the study and that no study data would be used for any purpose other than the study and would be discarded as soon as the study would finish. Third, an effort was made to maintain the anonymity and confidentiality of the study participants and the participants' regions and names were anonymized.

\section{Study result}

In this study, to find out implications for effective interventions for sexual minority clients, focus group interviews were conducted with 10 counselors with experience in sexual minority counseling and the results were analyzed using the Consensus Qualitative Research (CQR) method in which three researchers derived the concept, subcategories, and domains through discussion and agreement. As a result, a total of seven domains were created and 35 subcategories were derived for individual domains. Depending on how frequently each of the categories determined through the cross-tabulation was reported in the entire cases of interviews, the categories were divided into typical categories (those reported by in least five cases, that is, the majority of the entire cases) and variable categories (those reported in 2-4 cases). Categories reported in one case were regarded as exceptional categories and were excluded from analysis. [Table 2] shows the resultant frequencies by domain, category, and subcategory in this study.

Table 2. Results of cross-tabulation regarding the FIG of specialized sexualminority counselors

\begin{tabular}{|c|c|c|}
\hline Domain & Category & Frequency \\
\hline \multirow{2}{*}{$\begin{array}{l}\text { 1. Characteristics of sexual minority } \\
\text { clients }\end{array}$} & 1) Are under minority stress in addition to general stress & 8 (Typical) \\
\hline & 2) Do not feel safe even in counseling spaces & 5 (Typical) \\
\hline $\begin{array}{l}\text { 2. Difficulties of sexual minority } \\
\text { counselors }\end{array}$ & $\begin{array}{l}\text { 1) Great sense of helplessness because problems are } \\
\text { social structural problems }\end{array}$ & 5 (Typical)) \\
\hline \multirow{2}{*}{$\begin{array}{l}\text { 3. Effective counseling intervention } \\
\text { method }\end{array}$} & $\begin{array}{l}\text { 1) Interventions that give priority to the prevention of } \\
\text { trauma re-experience }\end{array}$ & 6 (Typical) \\
\hline & $\begin{array}{l}\text { 2) Integrated approach of diverse theories and } \\
\text { techniques }\end{array}$ & 5 (Typical) \\
\hline $\begin{array}{l}\text { 4. Changes in clients through } \\
\text { counseling }\end{array}$ & $\begin{array}{l}\text { 1) Psychological stability increases through self- } \\
\text { acception }\end{array}$ & 5 (Typical) \\
\hline \multirow{4}{*}{$\begin{array}{l}\text { 5. Matters that must be observed by } \\
\text { sexual minority counselors }\end{array}$} & 1) Observing basic counselor ethics & 6 (Typical) \\
\hline & 2) Mandatorily completing sex related education & 6 (Typical) \\
\hline & $\begin{array}{l}\text { 3) Acquiring and providing sufficient knowledge as an } \\
\text { expert }\end{array}$ & 6 (Typical) \\
\hline & $\begin{array}{l}\text { 4) Self-checking and reflecting as a counselor } \\
\text { minorities }\end{array}$ & 6 (Typical) \\
\hline
\end{tabular}

\section{Discussion and conclusion}


The specialized sexual minority counselors' counseling experiences are discussed centering on those that were shown to be typical in the results of this study as follows.

First, among the characteristics of the sexual minority clients, 'Are under minority stress in addition to general stress' and 'Do not feel safe even in counseling spaces' were shown to be typical and 'Have great difficulties due to family conflicts', 'Hard to find a support system', and 'Difficulties due to social Structural problems' were shown to be variable. These results are consistent with the findings of a previous study indicating that in environments where sexual minorities are hated, sexual minorities are isolated because they are not supported socially and they are under very intense stress sue to social alienation, rejection, and stigma [16]. In addition, these results are also consistent with other previous studies indicating that the recognition of social stigma negatively affect depression, anxiety, aggression, and suicide of sexual minorities [8][17][18] and those previous studies indicating that sexual minorities show higher morbidity of psychiatric diseases such as depression and anxiety disorders compared to heterosexuals [19]. These results are thought to show that our society still has a negative attitude toward sexual minorities and in which sexual minorities are in highly stressful situations.

Second, among the difficulties of sexual minority counselors, 'Great sense of helplessness because problems are social structural problems' was shown to be typical and 'Should pay more attention to the protection of clients who are the weak', 'Experienced indirect trauma by being identified with clients', 'Easily exhausted due to excessive role', 'Concerns about the influence of the gender identity of counselor', and 'Difficulties in forming counseling relationship' were shown to be variable. Counselors felt a sense of helplessness when the problems faced by sexual minorities could not be solved unless the social structures would be changed. These results are consistent with the findings of [7], who felt the need of a change in social awareness more than the need of efforts in counseling.

This is though to prove that many of the problems complained of by sexual minorities are difficulties related to the social structure.

Third, among the effective counseling intervention methods in domain 4, 'Interventions that give priority to the prevention of trauma re-experience' and 'Integrated approach of diverse theories and techniques' were shown to be typical and 'Regard counselor attitudes as important based on humanism', 'Identify and support the resources of clients', 'Evidencebased art therapeutic intervention', and 'Provide practical information for securing a support system' were shown to be variable. The fact that 'Interventions that give priority to the prevention of trauma re-experience' were shown to be typical can be regarded to indicate that a problem mainly complained of by sexual minorities is sexual minority related trauma. The suggestion of diverse intervention methods is thought to be related to the study findings indicating that sexual minority counseling is not much different from general counseling [5][7][11].

Fourth, among changes in clients through counseling, 'Psychological stability increases through self-acceptation' was shown to be typical and 'Expressions become freer thanks to the reduction in social distrust' and 'Practical pending problems of clients are solved' were shown to be variable. These findings are consistent with the report in a study conducted by [4] indicating that sexual minority youths experienced psychological stability, such as improved self-esteem and quality through counseling.

Fifth, among the matters that must be observed by sexual minority counselors, 'Observing basic counselor ethics Mandatorily completing sex related education', 'Mandatorily completing sex related education', 'Acquiring and providing sufficient knowledge as an expert', and 'Self-checking and reflecting as a counselor' were shown to be typical and 
'Respecting and accepting clients' words of now and here' and 'Respecting the sexual identity of sexual minorities' were shown to be variable. These findings are in the same context as the study findings indicating that eliminating prejudice is the most important for counselors [7][8], and those indicating that sexual minorities want counselors not to see them with prejudice against sexual orientation [4]. In addition, the above findings suggest that the counselor's effort to understand sexual minorities are necessary.

When the findings were put together, it was revealed that sexual minorities are under stress as minorities in addition to general stress, they feel difficulties to the extent that they do not feel even counseling spaces safe, and counselors feel a sense of helplessness when they counsel sexual minorities because many of sexual minorities' difficulties are due to social structural problems. As effective intervention methods for sexual minorities, interventions that give priority to the prevention of trauma reexperience and integrated approaches of diverse theories and techniques were pointed out. Through counseling, sexual minorities showed a change in psychological stability that was improved through self-acceptation. Counselors mentioned that among matters that must be observed by counselors in sexual minority counseling, observing basic counselor ethics, completing sex related education, acquiring sufficient knowledge of sexual minorities as an expert and providing the knowledge to sexual minority clients, and steadily carrying out self-checking and reflecting as a counselor were important.

The findings of this study are meaningful in that they give implications for effective intervention methods and matters that must be noted in sexual minority counseling, and that they can be used as basic data for developing sexual minority counseling manuals.

\section{Acknowledgements}

This study was carried out with the support of the Korea Research Foundation (Assignment Number, NRF-2017S1A5A2A01024668).

This study was reviewed by the Institutional Review Board (IRB) of Tongmyung University (TUIRB-2017-003).

\section{References}

[1] Pachankis J. E. and M. R. Goldfried, "Clinical issues in working with lesbian, gay and bisexual clients," Psychology of Sexual Orientation and Gender Diversity, vol.1, no.3, pp.45-58, (2013) DOI: 10.1037/00333204.41.3.227

[2] Woo S.R. and S.K. Yoo, "Counselor's reaction and clinical judgment according to counselor's negative attitude and competence in lesbian and gay counseling," The Korean Journal of Counseling and Psychotherapy, vol.29, no. 2, pp.311-334, (2017)

[3] Dorland J. M. and Fischer A. R. Gay, "lesbian, and bisexual individuals' perceptions: An analogue study," The Counseling Psychologist, vol.29, no.4, pp.532-547, (2001)

[4] Kim J.N, "Research on counseling experience: The sexual minority youth," Asia-Pacific Journal of Educational Management Research, vol.3, no.1, pp.1-6, (2019)

[5] Park J.E., "Influence of a counselor's discomfort towards a client on information processing of counselors: Focusing on homosexual client," M.S. thesis, Seoul National University, South Korea, (2013)

[6] Y.S. Seo, J.L. Lee, J.H. Kang, and J.H. Cha, "A study of the homophobic reactions of counselors," Korean Journal of Counseling and Psychotherapy, vol.19, no.2, pp.213-237, (2007)

[7] Yang H.S., "Consensual qualitative research on the sexual minority counseling experience of the counselors," M.S. thesis, Korea Counseling Graduate University, South Korea, (2017) 
[8] Lee M.J., "A phenomenological study on the Christian counselor's perception about LGBT in the Korean context," M.S. thesis, Seoul Women's University, South Korea, (2015)

[9] Laura B. F., E. W. Laura, and L.B. Penny, "Counselor competence with lesbian, gay and bisexual clients: Differences among practice settings," Journal of Multicultural Counseling and Development, vol.41, no.4, pp.194-209, (2013) DOI: 10.1002/j.2161-1912.2013.00036.x

[10] Valerie O. P. and B. Laura., "Exploring the clinical experiences of novice counsellors working with LGBT clients: Implications for training," Counselling and Psychotherapy Research, vol.14, no.1, pp.19-28, (2013) DOI: $10.1080 / 14733145.2013 .782055$

[11] Kim J.N, "Consensual qualitative research on the sexual minority counseling experience of the counselors," Asia Life Sciences Supplement, vol.19, no.2, pp.249-261, (2019)

[12] Israel T., and Hackett G, "Counselor education on lesbian, gay, and bisexual issues: Comparing information and attitude exploration," Counselor Education \& Supervision, vol.43, no.3, pp.179-191, (2004) DOI: 10.1002/j.1556-6978.2004.tb01841.x

[13] Rutter P. A., Estrada D., Ferguson L. K., and Diggs, G. A., "Sexual orientation and counselor competency: The impact of training on enhancing awareness, knowledge and skills," Journal of LGBT Issues in Counseling, vol.2, no.2, pp.109-125, (2008)

[14] Morgan D. I., “The focus group guidebook: Focus group kit 1.” SAGE Publication: CA, (1998)

[15] Morgan D. I. and Scannell A. U., "Planning Focus Groups (Fous Group Kit)," Thousand Oaks. CA: Sage. USA.pp.160, (1988)

[16] Yun G. H., "Homosexual Psychology,” Hakjisa, Seoul, South Korea, pp.346, (1997)

[17] Kang B.C., "A study on the process of how a perceived social stigma affects the life satisfaction of sexual minorities," Korean Journal of Social Welfare Studies, vol.42, no.2, pp.381-417, (2011)

[18] Huh J.E. "A study on the relationship between homosexuals of homosexuality-related stresses, depression and suicidal ideation,” M.S. thesis, Seoul Women's University, South Korea, (2004)

[19] Sandfort T. G., de Graaf R., Bijl R.V., and Schnabel P., "Same sex sexual behavior and psychiatric disorders: Findings from the Netherlands Mental Health Survey and Incidence Study (NEMESIS)," Archives of General Psychiatry, vol.58, no.1, pp.85-91, (2001) 
FGI Study on the Counseling Experience of Sexual Minority Counselors

This page is empty by intention. 